\title{
Sensitive Voltammetric Method for Piroxicam Determination in Pharmaceutical, Urine and Tap Water Samples using an Anodically Pretreated Boron-Doped Diamond Electrode
}

\author{
Hallyssonn Augusto Pires Rosseto ${ }^{1}$, Roberto Matos ${ }^{2}$, Roberta Antigo Medeiros ${ }^{2 *}$ \\ ${ }^{1}$ Universidade Estadual do Oeste do Paraná (Unioeste), Centro de Engenharias e Ciências Exatas, \\ 85903-000, Toledo, PR, Brazil \\ ${ }^{2}$ Universidade Estadual de Londrina (UEL), Centro de Ciências Exatas, Departamento de Química, \\ C.P. 10.011, 86057-970, Londrina, PR, Brazil
}

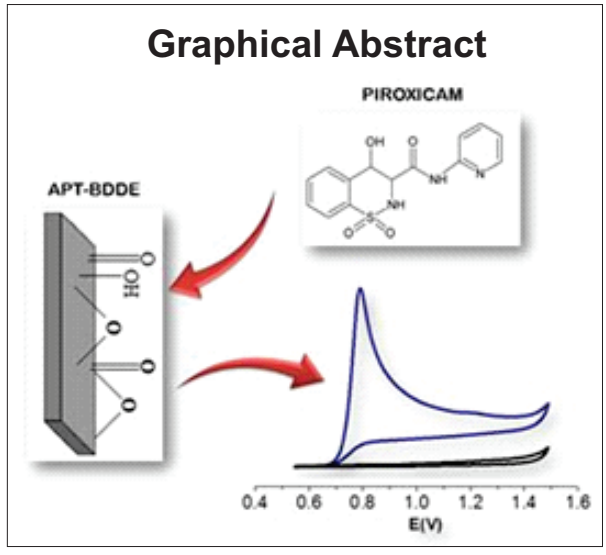

A simple and rapid voltammetric method for piroxicam (PRX) determination was developed using an anodically pretreated boron-doped diamond electrode and the square-wave voltammetric technique. Analytical curves were obtained for

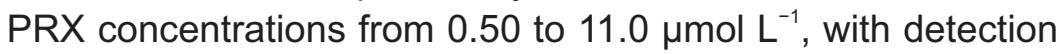
limits of $0.16 \mu \mathrm{mol} \mathrm{L} \mathrm{L}^{-1}$. The proposed method was successfully applied in the determination of PRX in pharmaceutical formulations (tablets), with results similar to those obtained using a reference spectrophotometric method (at a confidence level of $95 \%$ ), and in the recovery of PRX in synthetic urine and tap water samples.

Comparative to other electroanalytical methods based on different electrodes, the method yielded good results, being adequate for PRX determination in different samples with the advantage that it involves the use of a non-modified electrode.

Keywords: anti-inflammatory, anodic pretreatment, BDD electrode, square-wave voltammetry, electroanalytical method.

\section{INTRODUCTION}

In recent decades, nonsteroidal anti-inflammatory have been among the most frequently used medicinal drugs, and in many countries can be used without medical prescription [1]. Piroxicam (PRX), 4-hydroxy-2-methyl-N-(2-pyridinyl)-2H-1,2-benzothiazine-3-carboxamide 1,1-dioxide is a nonsteroidal anti-inflammatory drug of the oxicam class with analgesic, anti-inflammatory and antipyretic properties. It has been used in the treatment of rheumatoid arthritis, osteoarthrosis, ankylosing spondylitis and acute pain in muscular and skeletal disorders, and has been shown to be a suitable alternative for replacing other anti-inflammatory and analgesic drugs, such as aspirin, indomethacin, naproxen, ibuprofen, ketoprofen, sulindac, phenylbutazone and diclofenac in the treatment of rheumatic diseases [2, 3].

Currently, the drug PRX is classified as an emerging pollutant because it and its transformation products are continually released into the environment as a result of their manufacture, use (via excretion, mainly urine and feces) and disposal of unused and expired drugs, both directly into the domestic sewage system and via burial in landfills $[4,5]$.

Several analytical methods for assaying PRX in pharmaceutical formulations and human body fluids have been described in the literature [6-14]. Most of these methods use chromatographic and spectrophotometric techniques in which, commonly, organic toxic solvents are used, generating high amounts of waste, the analytical frequency is low and requires prior separation steps and the analytical process is tedious. 
Some electrochemical procedures also have been developed [15-23]; when compared to other types of procedure, they generally present good sensitivity, with the advantage of being relatively inexpensive, rapid, not using organic solvents and also having the possibility of analysis of colored solutions or solutions with suspended solids. Beltagi et al. [16] reported on the use of a hanging mercury drop electrode (HMDE) and square-wave voltammetry (SWV) technique to determine PRX in pharmaceuticals and human serum samples.

Years later, Shahrokhian et al. [17] developed a procedure for PRX determination in pharmaceuticals and clinical preparations using a pyrolytic graphite electrode modified with a film of carbon nanoparticlechitosan. In the same year Asadpour-Zeynali et al. [18] reported on the determination of PRX in pharmaceuticals using a chemically modified electrode based on a carbon ceramic electrode incorporated with zeolite ZSM-5 and a differential pulse voltammetric (DPV) method.

Next, a procedure using a PRX-selective molecularly imprinted polymer (MIP) and carbon paste electrode was reported by Gholivand et al. [19]. The MIP embedded in the carbon paste electrode behaves as a selective recognition element and pre-concentrator agent for PRX determination. Babaei et al. [20] developed a procedure for simultaneous determination of epinephrine and PRX using a nickel hydroxide nanoparticle/multiwalled carbon nanotube (CNT) composite electrode and cyclic voltammetry (CV), DPV and chronoamperometric techniques.

More recently, Gholivand et al. [21] also reported on the voltammetric oxidation of PRX at carbon paste and boehmite nanoparticle-modified carbon paste electrodes using anodic stripping DPV. Karimi-Maleh et al. [22] reported on the development of a modified N-(4-hydroxyphenyl)-3,5-dinitrobenzamide-FePt/CNT carbon paste electrode for the simultaneous determination of glutathione and PRX in hemolyzed erythrocyte, urine and pharmaceutical samples. Babaei et al. [23] developed a procedure using a glassy carbon (GC) electrode modified with a MCM-41/nickel hydroxide nanoparticle/multiwalled CNT composite as a sensor for the simultaneous determination of dopamine, PRX and cefixime in human urine and blood serum samples.

In the last few years, boron-doped diamond (BDD) has been extensively investigated as electrode material for electroanalytical procedures [24-27]. It presents interesting properties which make it particularly attractive for electroanalytical applications, such as a wide working potential window in aqueous solutions, chemical inertness, corrosion resistance, inertness of the surface to adsorption of reaction products, good resistance to passivation and a low and stable background [25,27].

The electroanalytical performance of a BDD electrode, for some analytes, might depend on their surface termination (hydrogen or oxygen), which can be obtained by cathodic (hydrogen termination) or anodic (oxygen termination) electrochemical pretreatment [28]. In the literature there are many works reported on the use of cathodically pretreated BDD to determine several organic substances, such as drugs, food additives and pollutants (see e.g. [29-36]). On the other hand, in some cases, better results were attained with an anodically pretreated BDD electrode (see e.g. [37-39]).

Considering the above, in this paper, we report on the influence of electrochemical pretreatment on the activity of a BDD electrode for PRX detection, as well as the optimization of a simple and rapid method for PRX determination in pharmaceutical formulations, synthetic urine and tap water samples without a previous separation step using the SWV technique.

\section{MATERIALS AND METHODS Apparatus}

CV and SWV experiments were performed using a PalmSens 2 (PalmSens) potentiostat/galvanostat controlled with PSTrace 4.6. A one-compartment three-electrode glass cell system was used for the electrochemical measurements, with a BDD (geometric area: $0.27 \mathrm{~cm}^{2}$ ) as working electrode, Pt wire as auxiliary electrode and an $\mathrm{Ag} / \mathrm{AgCl}\left(3.0 \mathrm{~mol} \mathrm{~L}^{-1} \mathrm{KCl}\right)$ reference electrode; hereinafter all potentials are referred to this reference electrode. 


\section{Article}

The BDD films obtained from NeoCoat (Switzerland), with specified 8000 ppm boron content were prepared by the hot-filament chemical vapor deposition technique on a monocrystalline silicon ( $p$-doped) substrate. Prior to the experiments, the BDD electrode was electrochemically pretreated by galvanostatic anodic (APT-BDD) or cathodic (CPT-BDD) polarization carried out in a $0.5 \mathrm{~mol} \mathrm{~L}^{-1} \mathrm{H}_{2} \mathrm{SO}_{4}$ solution. For the anodic pretreatment, $100 \mathrm{~mA} \mathrm{~cm}{ }^{-2}$ was applied for $30 \mathrm{~s}$, whereas for the cathodic pretreatment, $-100 \mathrm{~mA}$ $\mathrm{cm}^{-2}$ was applied for $180 \mathrm{~s}$.

After choosing the best BDD electrochemical pretreatment, the respective galvanostatic pretreatment procedure was carried out on the BDD electrode once at the beginning of every workday. The anodic pretreatment was chosen for the PRX determination, so first a cathodic pretreatment was always carried out followed by the anodic pretreatment to attain predominance of oxygen group terminations on the electrode surface.

The determination of PRX by a comparative spectrophotometric method [10] was carried out using a Shimadzu UV-1601 PC spectrophotometer (at $233 \mathrm{~nm}$ ), coupled to a microcomputer. Standard solutions at different PRX concentrations were prepared in alcoholic solution of hydrochloric acid to obtain the respective analytical curve.

\section{Reagents, supporting electrolytes and standards}

All reagents were of analytical grade. PRX was purchased from Sigma. Aqueous Britton-Robinson (BR) buffer solution ( $\left.0.04 \mathrm{~mol} \mathrm{~L}^{-1}\right)$ was used as supporting electrolyte. Buffer solutions were adjusted by adding the necessary amounts of $\mathrm{NaOH}$ in order to obtain the appropriate $\mathrm{pH}$ value. The $0.05 \mathrm{~mol} \mathrm{~L}^{-1}$ PRX stock solution was prepared in acetone, from which appropriate aliquots were diluted with the supporting electrolyte. All solutions were prepared using ultrapurified water (resistivity $>18 \mathrm{M} \Omega \mathrm{cm}$ ) supplied by a Milli-Q system (Millipore ${ }^{\circledR}$ ).

\section{Preparation of pharmaceutical formulations, synthetic human urine and tap water samples}

The proposed method was carried out for the determination of PRX in pharmaceutical formulations, synthetic human urine and tap water samples. Two commercial samples of pharmaceutical formulations (20 mg PRX/tablet) were purchased in a local market. Ten tablets of each analyzed pharmaceutical formulation were accurately weighed and finely powdered in a mortar, transferred into a calibrated flask and the volume completed with acetone to prepare a stock solution. After that, an appropriate aliquot was diluted with supporting electrolyte. The pharmaceutical formulation samples were analyzed using the standard addition method and the PRX contents found were compared with the label values and the values obtained with the spectrophotometric comparative method.

This method was then used to carry out recovery studies of PRX in different matrices: synthetic urine and tap water. The synthetic urine samples were prepared containing the majority of interferents present in real samples: $2.92 \mathrm{~g} \mathrm{NaCl}, 1.60 \mathrm{~g} \mathrm{KCl}, 1.10 \mathrm{~g} \mathrm{CaCl}_{2} .2 \mathrm{H}_{2} \mathrm{O}, 2.25 \mathrm{~g} \mathrm{Na}_{2} \mathrm{SO}_{4}, 1.40 \mathrm{~g} \mathrm{KH}_{2} \mathrm{PO}_{4}, 1.00 \mathrm{~g} \mathrm{NH}_{4} \mathrm{Cl}$ and $25.0 \mathrm{~g}$ of urea were dissolved in water in a $1.0 \mathrm{~L}$ volumetric flask, as previously done by Laube et al. [40]. This solution was used immediately after its preparation. An aliquot volume of fresh synthetic urine $(1.0 \mathrm{~mL})$ was placed into the electrochemical cell and filled up by supporting electrolyte to $10 \mathrm{~mL}$. Considering the range of the analytical curve, this solution was suitably spiked with standard solution of PRX. These recovery studies were done for two PRX concentrations $\left(2.5\right.$ and $\left.8.8 \mu \mathrm{mol} \mathrm{L}^{-1}\right)$ and the standard addition method was used.

The tap water sample was used for preparing the supporting electrolyte (BR buffer $0.04 \mathrm{~mol} \mathrm{~L}^{-1}$ ). Then, an aliquot volume of this solution $(10 \mathrm{~mL})$ was placed into the electrochemical cell and recovery studies were done for two PRX concentrations $\left(2.5\right.$ and $\left.8.8 \mu \mathrm{mol} \mathrm{\textrm {L } ^ { - 1 }}\right)$. The standard addition method was also used. 


\section{Measurement procedures}

All electrochemical measurements were carried out using a $10 \mathrm{~mL}$ electrochemical cell at room temperature $\left(25 \pm 1^{\circ} \mathrm{C}\right)$. Deaeration of the supporting electrolyte was not necessary, since no interference from $\mathrm{O}_{2}$ was detected under the studied experimental conditions.

CV and SWV were employed to investigate the electrochemical behavior and the quantification of PRX. The instrumental parameters for SWV were optimized and the respective analytical curve was obtained by adding small volumes of concentrated standard solutions of PRX to the supporting electrolyte solution (BR buffer $\mathrm{pH}$ 3.0). Limit of detection (LOD) values were calculated as three times the standard deviation for 10 measurements of the blank solution divided by the slope of the respective analytical curve [41]. The repeatability of the electroanalytical method was checked with intra-day $(n=10)$ and inter-day $(n=5)$ determinations for two different concentrations of $P R X$, for which the respective relative standard deviations (RSD) were calculated.

The selectivity of the proposed method was evaluated by the addition of possible interferents present in pharmaceutical formulations and urine samples (starch, magnesium stearate, lactose monohydrate, sodium lauryl sulfate, urea, uric acid) to a standard solution containing PRX, in the concentration ratios (standard solution to interferent) of 10,1 and 0.1 .

\section{RESULTS AND DISCUSSION}

\section{Electrochemical behavior of PRX and the influence of BDD electrochemical pretreatment}

Figure 1 presents the cyclic voltammograms (CVs) obtained for PRX using glassy carbon (GC) (dashed line) and BDD (solid line) electrodes. As can be seen, PRX presented an unique oxidation peak around 0.8 $\checkmark$ when a BDD electrode was used; moreover, the CVs obtained evidenced irreversible electrochemical behavior for PRX, in good agreement with data previously reported in the literature $[17,19]$.

The CV obtained for PRX using the GC electrode presented a higher capacitive current and a lower intensity faradaic current when compared with the BDD electrode, which shows the advantage of using BDD electrode for PRX determination.

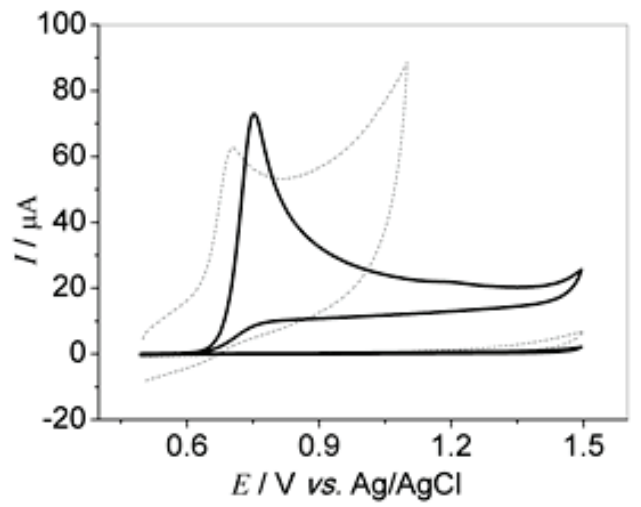

Figure 1. $\mathrm{CVs}\left(\mathrm{v}=50 \mathrm{mV} \mathrm{s}^{-1}\right)$ obtained for a $0.040 \mathrm{~mol} \mathrm{~L}^{-1} \mathrm{BR}$ buffer $\mathrm{pH} 3.0$ solution without and with $0.50 \mathrm{mmol} \mathrm{L}^{-1} \mathrm{PRX}$ solution using a BDD electrode (solid line) and a GC electrode (dashed line).

As previously described, anodic and cathodic pretreatment on the BDD electrode can activate its surface and provide a better electrochemical response for different analytes. As can be inferred from the obtained CVs shown in Figure 2, a better-defined response for PRX oxidation is obtained when an APT-BDD electrode is used. When the BDD electrode is cathodically pretreated, the intensity of the response is lower. Clearly, the surface enrichment of oxygen terminations caused by the anodic pretreatment of the BDD electrode leads to an enhanced interaction between the electrode and the analyte [42]; this might lead to an increase in the sensitivity and, consequently, to a decrease in the detection limit. 


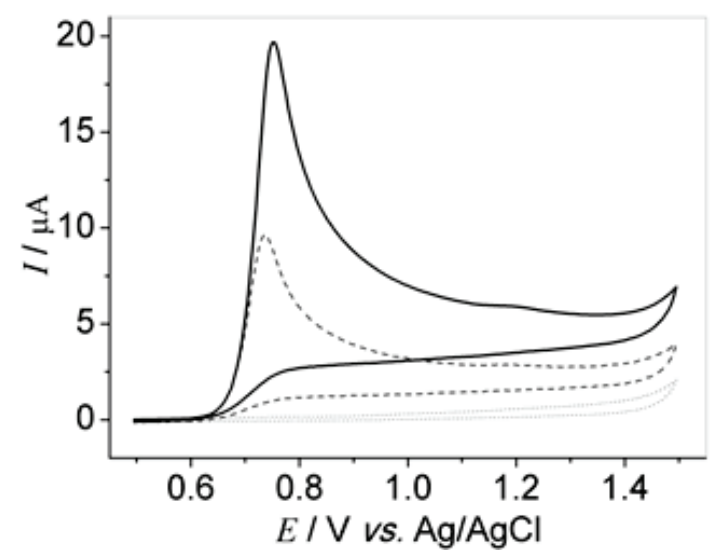

Figure 2. $\mathrm{CVs}\left(v=50 \mathrm{mV} \mathrm{s}^{-1}\right)$ obtained for a $0.040 \mathrm{~mol} \mathrm{~L}^{-1} \mathrm{BR}$ buffer $\mathrm{pH} 3.0$ solution without $\mathrm{PRX}$ (dot line) and with $0.50 \mathrm{mmol} \mathrm{L}^{-1} \mathrm{PRX}$ solution using an APT-BDD (solid lines) or CPT-BDD (dashed line) electrode.

\section{Effects of supporting electrolyte, $\mathrm{pH}$ and scan rate}

$\mathrm{CV}$ was used to investigate the effect of the supporting electrolytes $\left[0.10 \mathrm{~mol} \mathrm{~L}^{-1} \mathrm{H}_{2} \mathrm{SO}_{4}, 0.040 \mathrm{~mol} \mathrm{~L}^{-1}\right.$ BR buffer $(\mathrm{pH} 1.8)$ and $\left.0.10 \mathrm{~mol} \mathrm{~L}^{-1} \mathrm{KNO}_{3}(\mathrm{pH} 1.8)\right]$ on the redox activity of PRX using the APT-BDD electrode [see Figure 3(A)]. The best result was obtained with aqueous $0.040 \mathrm{~mol} \mathrm{~L}^{-1} \mathrm{BR}$ buffer $(\mathrm{pH} 1.8)$. The medium $\mathrm{pH}$ effect on the electrochemical signal of PRX was investigated. The $\mathrm{pH}$ of the $0.1 \mathrm{mmol} \mathrm{L}^{-1}$ PRX solutions was changed using BR buffer solutions in the range of $1.8-9.0$. The results are shown in Figure $3(\mathrm{~B})$. It was observed that the maximum oxidation peak current appeared at $\mathrm{pH}=3.0$. According to this figure, a pH higher than 3.0 leads to a decrease in the peak current values. Thus, $\mathrm{pH} 3.0$ was fixed by BR buffer solutions for PRX determination.
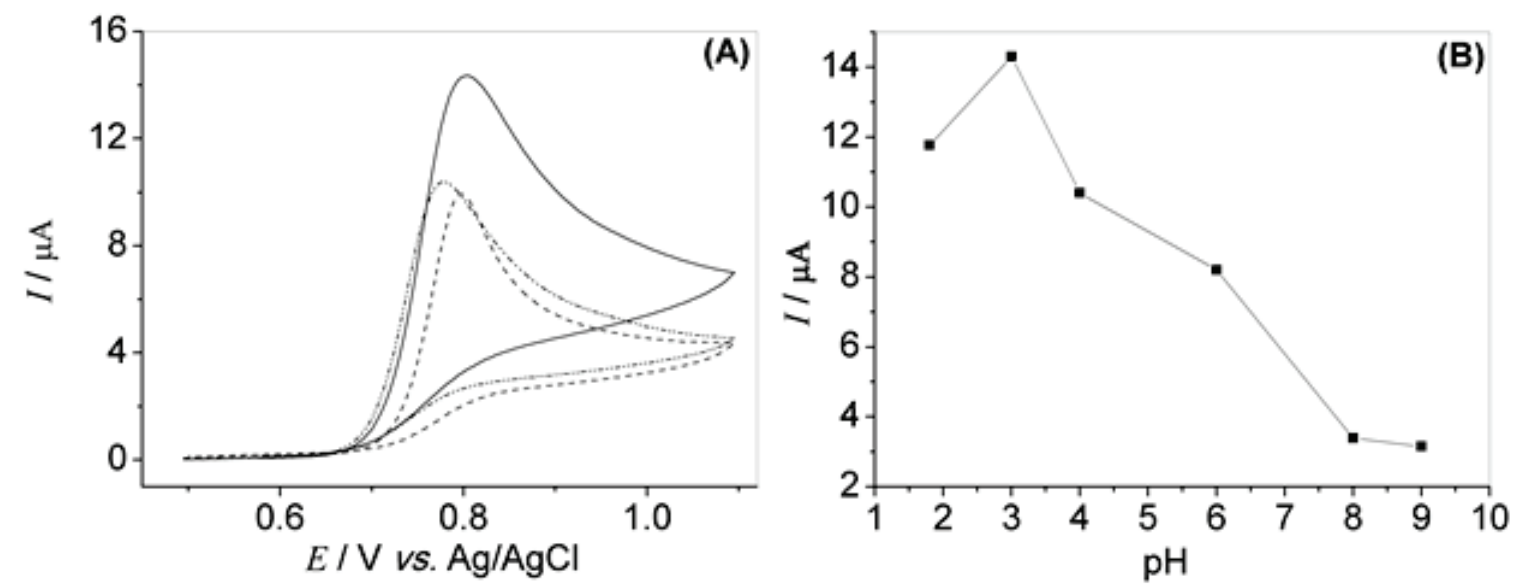

Figure 3. (A) CVs $\left(50 \mathrm{mV} \mathrm{s}^{-1}\right)$ obtained for $0.10 \mathrm{mmol} \mathrm{L}^{-1} \mathrm{PRX}$ using an APT- BDD electrode in different supporting electrolytes: $0.10 \mathrm{~mol} \mathrm{~L}^{-1} \mathrm{H}_{2} \mathrm{SO}_{4}$ (dashed line), $0.040 \mathrm{~mol} \mathrm{~L}^{-1} \mathrm{BR}$ buffer $\mathrm{pH} 1.8$ (solid line) and $0.10 \mathrm{~mol} \mathrm{~L}^{-1} \mathrm{KNO}_{3} \mathrm{pH} 1.8$ (dashed dot line). (B) Peak current for oxidation of $0.10 \mathrm{mmol} \mathrm{L}^{-1} \mathrm{PRX}$ in $\mathrm{BR}$ buffer at different $\mathrm{pH}$, scan rate: $50 \mathrm{mVs}^{-1}$.

The effect of scan rate $(v)$ on the peak current $\left(I_{\mathrm{p}}\right)$ for $0.10 \mathrm{mmol} \mathrm{L} \mathrm{L}^{-1} \mathrm{PRX}$ was studied [see Figure $4(\mathrm{~A})$ ]. Was observed that the oxidation peak shifted towards the positive direction with the increasing of scan rate, which was one of the characteristic features of the irreversible electrode reactions. A linear relationship was observed between the oxidation peak current and the square root of the scan rate $\left[\left(I_{\mathrm{p}}(\mu \mathrm{A})=0.406+\right.\right.$ $44.9 v^{1 / 2}\left(\mathrm{mV} \mathrm{s}^{-1}\right)^{1 / 2} ; r=0.992$ ] [see Figure $\left.4(B)\right]$.

The slope of the plot of $\log I_{\mathrm{p}}$ vs. $\log v$ [see Figure $4(\mathrm{C})$ ] was 0.408 , which is close to the theoretical value of 0.5 (expected for an ideal reaction based on a diffusion-controlled electrode process) [43]. Hence, for the APT-BDD electrode, the electrooxidation of PRX is clearly a diffusion-controlled process. 

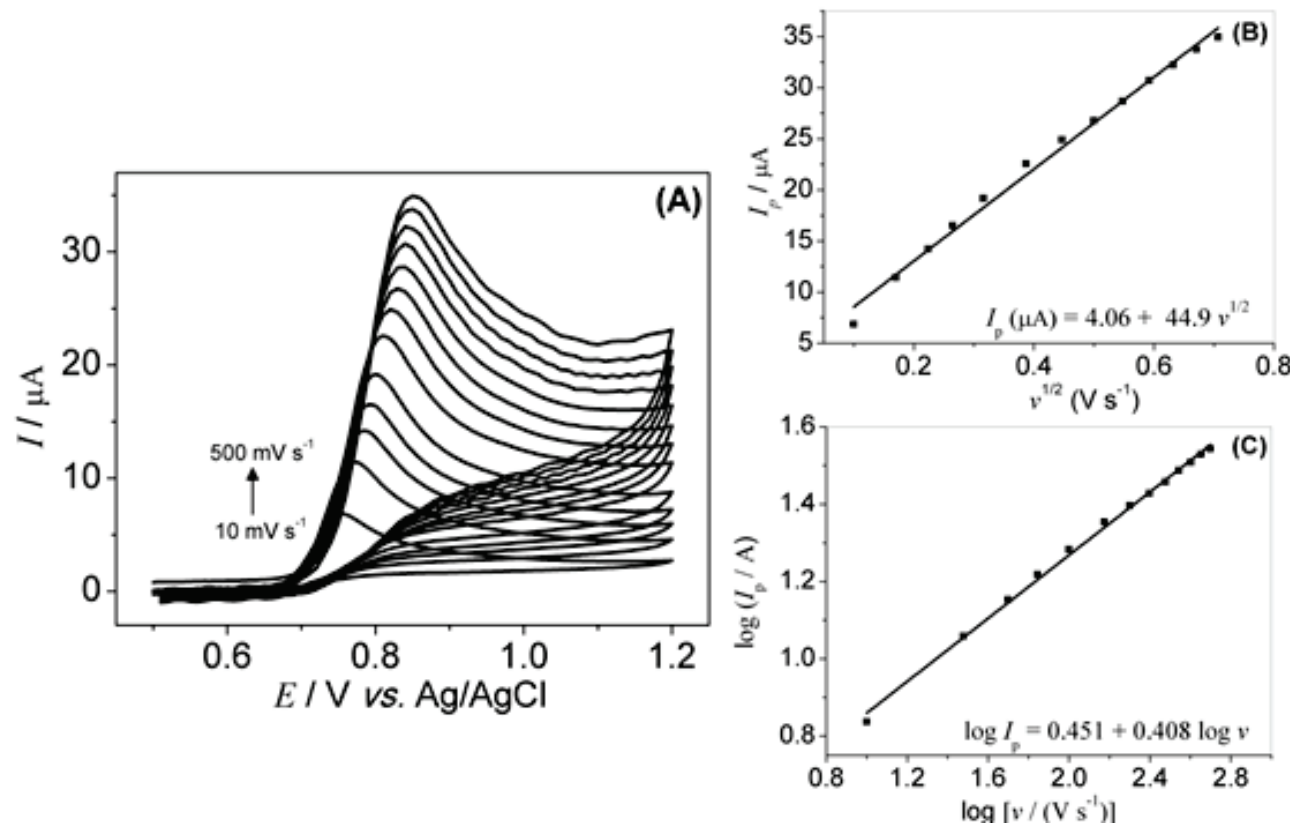

Figure 4. (A) CVs obtained for $0.10 \mathrm{mmol} \mathrm{L}^{-1} \mathrm{PRX}$ in different scan rates $\left(10-500 \mathrm{mVs}^{-1}\right)$ using an APT- BDD electrode in a $0.040 \mathrm{~mol} \mathrm{~L}^{-1} \mathrm{BR}$ buffer $\mathrm{pH} 3.0$; (B) linear dependence of $I_{\mathrm{p}}$ with $v^{1 / 2}$; (C) Logarithm of the $I_{\mathrm{p}}$ as a function of the logarithm of the scan rate $(v)$.

\section{Optimization of the SWV parameters}

The most important parameters that influence the signal response obtained for PRX by SWV are the square-wave amplitude $(a)$, square-wave frequency $(f)$ and the increment of the staircase height $\left(E_{s}\right)$. When $E_{\mathrm{s}}$ was changed from 1 to $6 \mathrm{mV}$, and the remaining parameters were constant $(f=60 \mathrm{~Hz}, a=50$ $\mathrm{mV}$ ), the current peak signal increased rapidly until the value of $5 \mathrm{mV}$ followed by a slow increase from 6 $\mathrm{mV}$. The $E_{\mathrm{s}}$ of $5 \mathrm{mV}$ was chosen for the next experiments. The influence of a was studied in the range from 10 to $100 \mathrm{mV}$ (remaining parameters: $E_{\mathrm{s}}=5 \mathrm{mV}, f=60 \mathrm{~Hz}$ ). The current peak signal of PRX rapidly increased until $50 \mathrm{mV}$. Nevertheless, the peak became wider and deformed and thus the amplitude of 50 $\mathrm{mV}$ was chosen for the next experiments.

When the frequency changed from 10 to $100 \mathrm{~Hz}\left(E_{\mathrm{s}}=5 \mathrm{mV}, a=50 \mathrm{mV}\right)$ the peak current signal increased linearly. However, the peak became wider for $f$ above $60 \mathrm{~Hz}$. Thus, $f=60 \mathrm{~Hz}$ was selected for all subsequent experiments.

According to SWV theory [44] the number of electrons transferred in the redox process can be investigated using the relationship:

$$
\Delta E_{\mathrm{p}}=\Delta \log f=-2.3 \mathrm{RTa} / \mathrm{nF}
$$

Where $\alpha$ is the transfer coefficient and $n$ the number of electrons involved in the redox reaction, the other terms having their usual meaning. The slope obtained from the $E_{p}$ vs. log $f$ plot was 0.0608 (results not shown); thus, by means of Eq. (1), values equal to $0.970 \mathrm{~V}$ were determined for an. If the a value of is assumed as equal to 0.5 , a common feature for organic molecules, these results indicate that the oxidation of PRX involves two electrons per molecule. From these results and considering the proposed PRX oxidation mechanisms in the literature $[21,45]$ it is believed that the PRX electrochemical oxidation occurs by a two-electron mechanism (see Figure 5). 


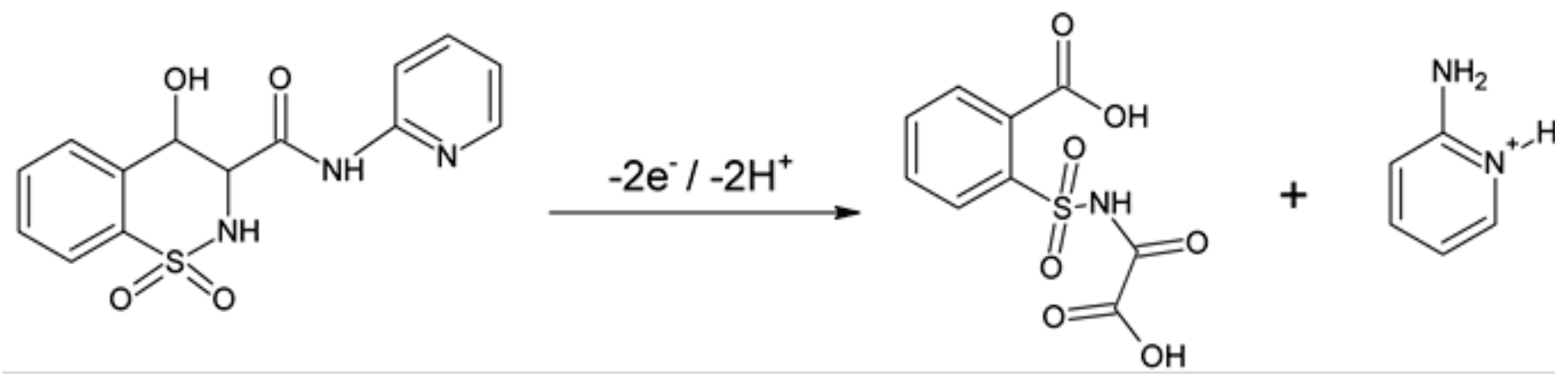

Figure 5. Eletrooxidation reaction mechanism for PRX.

\section{Analytical conditions for the determination of PRX using an anodically pretreated BDD electrode}

After these studies, an analytical curve was obtained for PRX in $0.040 \mathrm{~mol} \mathrm{~L}^{-1} \mathrm{BR}$ buffer $(\mathrm{pH} 3.0)$ in the concentration range 0.50 to $11.0 \mu \mathrm{mol} \mathrm{L}^{-1}$. As can be seen in Figure $6, I_{\mathrm{p}}$ increases proportionally with the PRX concentration (all measurements were performed in triplicate) and the corresponding calibration equation was:

$$
\left(I_{\mathrm{p}} / \mu \mathrm{A}\right)=-(0.06 \pm 0.06)+(4.1 \pm 0.4) \times 10^{5}[\mathrm{PRX}] ; \mathrm{r}^{2}=0.996
$$

The LOD obtained was $1.6 \times 10^{-7} \mathrm{~mol} \mathrm{~L}^{-1}$. The linear concentration ranges and LOD values obtained for PRX determination using different electrodes and electrochemical techniques are presented in Table I. From these data, it can be inferred that the performance attained with the APT-BDD electrode is comparatively good. Furthermore, the method proposed here involves the use of a non-modified electrode, which generally increases the analytical frequency and precision of the electroanalytical method.

Then, intra- and inter-day repeatability was assessed by successive determination of PRX at different concentrations: $9.9 \times 10^{-7}$ and $1.1 \times 10^{-5} \mathrm{~mol} \mathrm{~L}^{-1}$. The obtained RSD values lower than $6.5 \%$ (results not shown) attest the excellent stability and repeatability of the APT-BDD electrode response in the oxidation of PRX.

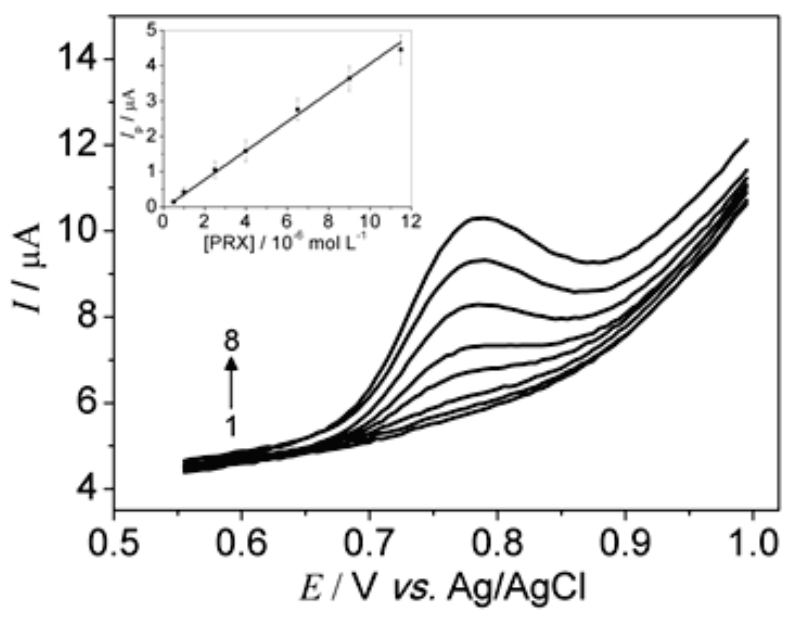

Figure 6. Square wave voltammograms for various concentrations of PRX using an APT-BDD electrode in BR buffer pH 3.0 (2-8): 0.5; 1,0; 2,5; 4,0; 6,5; 9,0; $11.0 \mu \mathrm{mol} \mathrm{L}^{-1}$. Inset: the respective analytical curve for PRX. 
Table I. Comparison of results obtained for the determination of PRX by the here-proposed method and by other electrochemical methods reported in the literature

\begin{tabular}{|c|c|c|c|}
\hline Electrode & Linear range $\left(\mathrm{mol} \mathrm{L}^{-1}\right)$ & $L O D^{*}\left(\mathrm{~mol} \mathrm{~L}^{-1}\right)$ & Ref. \\
\hline HMDE & $2.0 \times 10^{-10}-2.0 \times 10^{-8}$ & $5.4 \times 10^{-11}$ & 16 \\
\hline CS-CNP-PGE ${ }^{A}$ & $5.0 \times 10^{-8}-5.0 \times 10^{-5}$ & $2.5 \times 10^{-8}$ & 17 \\
\hline $\mathrm{CCZME}^{\mathrm{B}}$ & $2.0 \times 10^{-7}-2.0 \times 10^{-5}$ & $6.5 \times 10^{-7}$ & 18 \\
\hline $\mathrm{MIP}-\mathrm{CP}^{\mathrm{C}}$ & $2.0 \times 10^{-9}-1.9 \times 10^{-7}$ & $5.0 \times 10^{-10}$ & 19 \\
\hline MWCNTs-NHNPs/GCE ${ }^{\mathrm{D}}$ & $7.0 \times 10^{-7}-7.5 \times 10^{-5}$ & $1.1 \times 10^{-7}$ & 20 \\
\hline $\mathrm{BNP}-\mathrm{CP}^{\mathrm{E}}$ & $5.0 \times 10^{-10}-1.0 \times 10^{-7}$ & $1.1 \times 10^{-10}$ & 21 \\
\hline NHPDA/FePt/CNTs/CPE ${ }^{F}$ & $5.0 \times 10^{-7}-5.5 \times 10^{-4}$ & $1.0 \times 10^{-7}$ & 22 \\
\hline MWCNTs-NHNPs-MCM-41/GCE ${ }^{G}$ & $1.0 \times 10^{-7}-7.0 \times 10^{-5}$ & $4.0 \times 10^{-8}$ & 23 \\
\hline BDD & $5.0 \times 10^{-7}-1.1 \times 10^{-5}$ & $1.6 \times 10^{-7}$ & This work \\
\hline
\end{tabular}

* $L O D$ - limit of detection

${ }^{A}$ basal-plane pyrolytic graphite electrode coated with a thin film of chitosan/carbon nanoparticles

${ }^{\mathrm{B}}$ carbon ceramic zeolite modified electrode

${ }^{\mathrm{c}}$ carbon Paste Electrode Modified with an MIP

${ }^{\mathrm{D}}$ nickel hydroxide nanoparticles/multiwalled carbon nanotubes composite electrode

${ }^{\mathrm{E}}$ boehmite nanoparticles modified carbon paste

${ }^{F} \mathrm{~N}$-(4-hydroxyphenyl)-3,5-dinitrobenzamide-FePt/CNTscar-bon paste electrode

${ }^{G}$ multiwalled carbon nanotubes (MWCNTs), nickel hydroxide nanoparticles (NHNPs), and MCM-41 modified glassy carbon electrode.

\section{Determination of PRX in pharmaceutical formulations, synthetic human urine and tap water samples}

Prior to the analysis of samples, the selectivity of the proposed method was evaluated by the addition of possible interferents (starch, magnesium stearate, lactose monohydrate, sodium lauryl sulfate, urea and uric acid) to a standard solution containing PRX at the concentration ratios (standard solution to interferent) of 10, 1 and 0.1 The current signals obtained in the presence of these possible interferents were compared with those obtained with the standard solution (data not shown) and no significant differences were found, presented Relative Errors lower than $8.6 \%$; therefore, we could conclude that those compounds do not significantly interfere with the method proposed here.

After that, the proposed method was applied to determination of PRX in pharmaceutical formulation samples. The results are reported in Table II and were compared with the results obtained with the spectrophotometric method [10]. The analytical curve obtained present a linear range concentration of 3.0 to $30.0 \mu \mathrm{mol} \mathrm{L}^{-1}$ and the calibration equation was:

$$
\text { Abs }=(1.16 \pm 0.05) \times 10^{-3}+(2.74 \pm 0.07) \times 10^{4}[P R X] ; r^{2}=0.999
$$

The representative voltammograms for determination of PRX in pharmaceutical formulations using the standard addition method are depicted in Figure 7. By analyzing the obtained results shown in Table II, one can conclude that the values obtained by the proposed method agree quite well with those obtained by the comparative method. Applying a paired $t$-test to the results obtained using these methods, the resulting $t$ value $(1.41)$ is smaller than the critical one $(12.7, \alpha=0.05)$, indicating that there is no difference between the obtained results at a confidence level of $95 \%$. 


\section{Article}

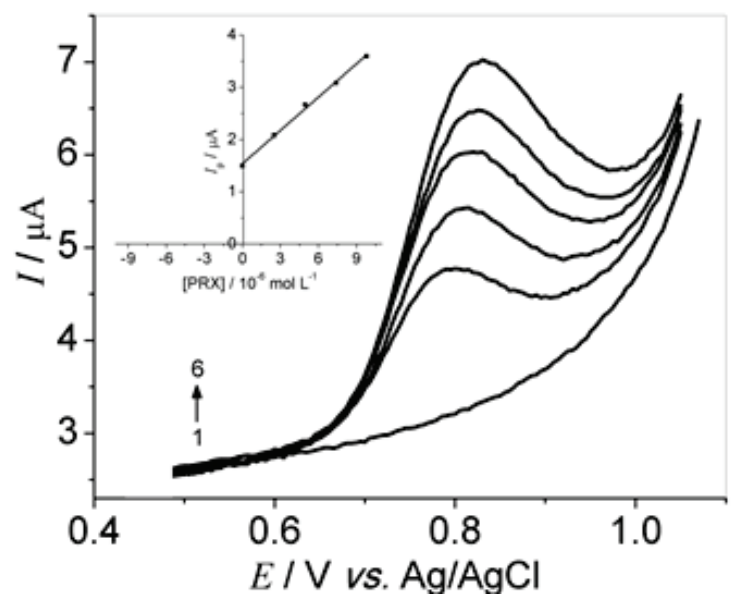

Figure 7. Square wave voltammograms for PRX determination in pharmaceutical formulation sample by the standard addition method using an APT- BDD electrode in BR buffer pH 3.0. Concentration of PRX standard solution added: (3-6): 2.49; 4.95; 7.39 and $9.80 \mu \mathrm{mol} \mathrm{L}^{-1}$. Inset: the respective analytical curve for PRX determination in pharmaceutical formulation sample.

Table II. Results obtained for PRX determination in pharmaceutical formulations by the proposed method and by spectrophotometric comparative method

\begin{tabular}{cccc}
\hline \multicolumn{4}{c}{ PRX mass per tablet / mg } \\
\hline Samples & $\begin{array}{c}\text { Reference } \\
\text { Method }\end{array}$ & $\begin{array}{c}\text { Proposed } \\
\text { Method* }\end{array}$ & $\begin{array}{c}E^{\mathrm{A}} \\
(\%)\end{array}$ \\
\hline A & $23 \pm 1$ & $21 \pm 2$ & -8.7 \\
B & $23 \pm 1$ & $23 \pm 1$ & 0.0 \\
\hline
\end{tabular}

${ }^{*} n=3$

${ }^{A}$ Relative error $(\%)=100 \times($ proposed method value reference method value) / reference method value.

Then, to increase the applicability of the proposed method, samples of synthetic urine and tap water were spiked with PRX at two different concentrations and analyzed employing the standard addition method under the optimized experimental conditions. The choice of these samples was realized considering that $5 \%$ of PRX are excreted in unaltered form in urine and that it was classified as emerging pollutant $[46,47]$. As can be inferred from the results shown in Table III, the novel electroanalytical method reported here yielded adequate percentage recovery values (ranging from 99 to 104\%). Clearly, the method does not suffer any significant matrix interference and thus is potentially applicable in the determination of PRX in these samples kind.

Table III. Results obtained for PRX determination in synthetic urine and tap water samples by the proposed methods

\begin{tabular}{lccc}
\hline Samples & $\begin{array}{c}\text { Added } \\
\left(\mu \mathrm{mol} \mathrm{L}^{-1}\right)\end{array}$ & $\begin{array}{c}\text { Found } \\
\left(\mu \mathrm{mol} \mathrm{L}^{-1}\right)\end{array}$ & $\begin{array}{c}\text { Rec. }^{*} \\
(\%)\end{array}$ \\
\hline Urine & & & \\
A & 2.49 & $2.47 \pm 0.01$ & 99.2 \\
B & 8.80 & $9.21 \pm 0.09$ & 104 \\
\hline Tap water & & & \\
A & 2.49 & $2.59 \pm 0.07$ & 104 \\
B & 8.80 & $8.86 \pm 0.04$ & 101 \\
\hline${ }^{*}(\mathrm{n}=3) ;$ Rec.: Recovery & &
\end{tabular}




\section{CONCLUSIONS}

The present study shows that the electroanalytical performance of the BDD electrode in the detection of PRX is significantly enhanced by an anodic (galvanostatic) pretreatment, which leads to a predominantly oxygen-terminated electrode surface. CV and SWV studies have shown that the PRX electrooxidation is controlled by a diffusion-electrode process and occurs by a two-electron mechanism.

Then, an electroanalytical method for PRX determination using an APT-BDD electrode and SWV was developed. Optimization of the experimental parameters yielded a linear range from 0.50 to $11.0 \mu \mathrm{mol} \mathrm{L}^{-1}$ and an LOD of $0.16 \mu \mathrm{mol} \mathrm{L} \mathrm{L}^{-1}$ for $\mathrm{PRX}$ in $\mathrm{BR}$ buffer solution ( $\mathrm{pH}$ 3.0). No absorption effects were observed on the BDD electrode, without the necessity of renovating its surface after each measurement.

Furthermore, when this method was applied in the determination of PRX in pharmaceutical formulations (tablets), the results obtained were statistically equal (at a confidence level of 95\%) to those obtained using a comparative spectrophotometric method. Moreover, addition-recovery determination of PRX in synthetic human urine and tap water samples yielded adequate results, indicating the potential application of the SWV method in the determination of PRX in real samples.

Finally, the novel SWV method reported here is simple, relatively inexpensive and rapid, with the significant advantage that non-modified electrodes are used, which increases its analytical frequency and precision.

Manuscript received Oct. 4, 2017; revised version received Dec. 4, 2017; accepted Jan. 10, 2018.

\section{REFERENCES}

1. Ungprasert, P.; Cheungpasitporn, W.; Crowson, C. S.; Matteson, E. L. Eur. J. Intern. Med. 2015, 26, pp 285-291.

2. Brogden, R. N.; Heel, R. C.; Speight, T. M.; Avery, G. S. Drugs, 1984, 28, pp 292-323.

3. Verbeeck, R. K.; Blackburn, J. L.; Loewen, G. R. Clin. Pharmacokinet. 1983, 8, pp 297-331.

4. Vera-Candioti, L.; Garcia, M. D. G.; Galera, M. M.; Goicoechea, H. C. J. Chromatogr. A, 2008, 1211, pp 22-32.

5. Hurtado-Sanchez, M. D.; Lozano, V. A.; Rodriguez-Caceres, M. I. Talanta 2015, 134, pp 215-223.

6. Baranowska, I.; Markowski, P.; Baranowski, J. Anal. Sci. 2009, 25, pp 1307-1313.

7. Sultana, N.; Arayne, M. S.; Ali, S. N. J Sep. Sci. 2013, 36, pp 3176-3183.

8. Khan, I.; Ashfaq, M.; Razzaq, S.; Mariam, I. J. Liq. Chromatogr. Relat. Technol. 2013, 36, pp 14371450.

9. Vera-Candioti, L.; García, M. D. G.; Galera, M. M.; Goicoechea, H. C. J. Chromatogr. A, 2008, 1211, pp 22-32.

10. Pereira, A.; Scheshowitsch, K.; Cruz, A.; Silva, M. A. S.; Stulzer, H. K. Visão Acadêmica, 2007, 8, pp 29-37.

11. Demiralay, E. C.; Alsancak, G.; Ozkan, S. A. J. Sep. Sci. 2009, 32, pp 2928-2936.

12. Amin, A. S.; Dessouki, H. A.; Khalil, K. M. Bull. Chem. Soc. Ethiop. 2010, 24, pp 121-126.

13. Dragomiroiu, G. T. A. B.; Cimpoiesu, A.; Ginghina, O.; Baloescu, C.; Barca, M.; Popa, D. E.; Ciobanu, A. M.; Anuta, V., T. Farmacia 2015, 63, pp 123-131.

14. Dal, A. G.; Oktayer, Z.; DoLrukol-Ak, D. J. Anal. Methods Chem. 2014, 2014, pp 1-7.

15. Acuña, J. A.; Fuente, C. D. L.; Vãzquez, M. D.; Tascón, M. L.; Sánchez-Batanero, P. Talanta, 1993, 40, pp 1637-1642.

16. Beltagi, A. M.; Abdallah, O. M.; Ghoneim, M. M. Chem. Anal. 2007, 52, pp 387-398. 


\section{Article}

17. Shahrokhian, S.; Jokar, E.; Ghalkhani, M. Microchim. Acta 2010, 170, pp 141-146.

18. Asadpour-Zeynali, K.; Majidi, M.; Zarifi, M. Cent. Eur. J. Chem. 2010, 8, pp 155-162.

19. Gholivand, M. B.; Karimian, N. Mater. Sci. Eng., C, 2011, 31, pp 1844-1851.

20. Babaei, A.; Sohrabi, M.; Afrasiabi, M., A. Electroanalysis 2012, 24, pp 2387-2394.

21. Gholivand, M. B.; Malekzadeh, G.; Derakhshan, A. A. Sens. Actuators, B, 2014, 201, pp 378-386.

22. Karimi-Maleh, H.; Tahernejad-Javazmi, F.; Ensafi, A. A.; Moradi, R.; Mallakpour, S.; Beitollahi, H. Biosens. Bioelectron. 2014, 60, pp 1-7.

23. Babaei, A.; Afrasiabi, M. Ionics, 2015, 21, pp 1731-1740.

24. Compton, R. G.; Foord, J. S.; Marken, F. Electroanalysis 2003, 15, pp 1349-1363.

25. Luong, J. H. T.; Male, K. B.; Glennon, J. D. Analyst, 2009, 134, pp 1965-1979.

26. Peckova, K.; Musilova, J.; Barek, J. Crit. Rev. Anal. Chem. 2009, 39, pp 148-172.

27. Einaga, Y.; Foord, J. S.; Swain, G. M. MRS Bull, 2014, 39, pp 525-532.

28. Salazar-Banda, G. R.; Andrade, L. S.; Nascente, P. A. P.; Pizani, P. S.; Rocha-Filho, R. C.; Avaca, L. A. Electrochim. Acta, 2006, 51, pp 4612-4619.

29. Codognoto, L.; Tanimoto, S. T.; Pedrosa, V. A.; Suffredini, H. B.; Machado, S. A. S.; Avaca, L. A. Electroanalysis 2006, 18, pp 253-258.

30. Deroco, P. B.; Vicentini, F. C.; Oliveira, G. G.; Rocha-Filho, R. C.; Fatibello-Filho, O. J. Electroanal. Chem. 2014, 719, pp 19-23.

31. Brocenschi, R. F.; Rocha-Filho, R. C.; Biaggio, S. R.; Bocchi, N. Electroanalysis 2014, 26, pp 15881597.

32. Lourencao, B. C.; Baccarin, M.; Medeiros, R. A.; Rocha-Filho, R. C.; Fatibello-Filho, O. J. Electroanal. Chem. 2013, 707, pp 15-19.

33. Janegitz, B. C.; Medeiros, R. A.; Rocha-Filho, R. C.; Fatibello-Filho, O. Diam. Relat. Mat. 2012, 25, pp 128-133.

34. Medeiros, R. A.; de Carvalho, A. E.; Rocha-Filho, R. C.; Fatibello-Filho, O. Quim. Nova 2008, 31, pp 1405-1409.

35. Mansano, G. R.; Eisele, A. P. P.; Dall'Antonia, L. H.; Afonso, S.; Sartori, E. R., J. Electroanal. Chem. 2015, 738, pp 188-194.

36. Sartori, E. R.; Trench, A. B.; Rocha-Filho, R. C.; Fatibello-Filho, O., J. Braz. Chem. Soc. 2013, 24, pp 1504-1511.

37. Deroco, P. B.; Medeiros, R. A.; Rocha-Filho, R. C.; Fatibello-Filho, O. Anal. Meth. 2015, 7, pp 21352140.

38. Lourencao, B. C.; Medeiros, R. A.; Thomasi, S. S.; Ferreira, A. G.; Rocha-Filho, R. C.; FatibelloFilho, O. Sens. Actuators, B, 2016, 222, pp 181-189.

39. Andrade, L. S.; de Moraes, M. C.; Rocha-Filho, R. C.; Fatibello-Filho, O.; Cass, Q. B. Anal. Chim. Acta, 2009, 654, pp 127-132.

40. Laube, N.; Mohr, B.; Hesse, A. J. Cryst. Growth, 2001, 233, pp 367-374.

41. ICH International Conference on Harmonisation, Validation of Analytical Procedures: Text and Methodology. www.ich.org

42. Brocenschi R. F.; Hammer P.; Deslouis C.; Rocha-Filho R. C. Anal. Chem. 2016, 88, pp 5363-5368.

43. Grosser, D. K., Cyclic voltammetry simulation and analysis of raction mechanisms. VCH Publisher: New York, 1994.

44. Scholz, F., Electroanalytical methods. Springer: New York, 2005. 